\title{
The Development of Malcolm Baldrige-Based Patient Safety Model in Basic Emergency Obstetric Care Community Health Center (BEOC-CHC). Preliminary Study: Implementation of Patient Safety in Padang
}

\author{
Dien Gusta Anggraini Nursal, ${ }^{1,2}$, Rizanda Machmud ${ }^{1}$, Eryati Darwin¹, \\ Nana Mulyana ${ }^{3}$, and Riska Yolanda ${ }^{4}$ \\ ${ }^{1}$ Faculty of Medicine, Andalas University, Padang, Indonesia \\ ${ }^{2}$ Faculty of Public Health, Andalas University, Padang, Indonesia \\ ${ }^{3}$ Ministry of Health Republic of Indonesia, Jakarta, Indonesia \\ ${ }^{4}$ Postgraduate Student Faculty of Public Health, Universitas Indonesia, Depok, Indonesia
}

Corresponding Author:

Dien Gusta Anggraini Nursal

diennursal@fkm.unand.ac.id

Received: 26 December 2018 Accepted: 23 February 2019 Published: 7 March 2019

Publishing services provided by Knowledge E

(c) Dien Gusta Anggraini Nursal et al. This article is distributed under the terms of the

Commons Attribution License, which permits unrestricted use and redistribution provided that the original author and source are credited

Selection and Peer-review under the responsibility of the $2 \mathrm{nd}$ International Meeting of Public Health 2016 Conference Committee.

\section{Abstract}

A high number of Adverse Event based on the data from Ministry of Health RI showed that patient safety was still not going well, while patient safety was a measure of the quality of health services in Indonesia. The purpose of this study was to determine the implementation of the seven standards of patient safety as the basis of patient safety model development based on Malcolm Baldrige in BEOC - $\mathrm{CHC}$ of Padang as the implementation of maternal and child protection. This study used a qualitative research method, and the number of the informant was 25 - the data collecting was done by in-depth interview and Focus Group Discussion that would be written on the transcript in the form of a matrix and analyzed through resource and method triangulation. Based on the study result, there were no guidelines about patient safety from Department of Health of West Sumatera to the BEOC - $\mathrm{CHC}$; it also obtained that the patient safety incident that occurred in the form of patient falls, diagnostic errors and drug delivery personally without reporting to the Department of Health. Out of seven standards of patient safety, it was only the third standard that has accomplished. It could be concluded that patient safety hadn't been entirely implemented, so it was necessary to develop Malcolm Baldrige-based patient safety model that was suitable to improve patient safety in BEOC - $\mathrm{CHC}$

Keywords: Patient Safety; BEOC; MBNQA

\section{Introduction}

WHO had identified the risk of an adverse event in health services which were dangerous and they threaten the safety of patients globally (Damayanti and Rosdiana 2016). Risks were detected since the Institute of Medicine (IOM) reported adverse events on 
the hospital in Utah and Colorado by $2.9 \%$ which $6.6 \%$ of them died, and the New York Hospital by $3.7 \%$ with the mortality rate was $13.6 \%$ of them (Findyartini et al. 2015; Kohn et al. 2000; Marchon and Mendes Junior 2014). The report of the adverse event in Indonesia from the Ministry of Health was quite low. Until February 2016, it just reached 289 stories. The type of adverse event consistedof 69 incidents of near miss (43.67\%) in the form of medication errors (29.2\%), patient falls (23.4\%), canceled operations (14.3\%), diagnosis errors (11\%), incorrect laboratory tests (8.4\%) and inaccurate roentgen $(5.2 \%)$ (Sub-Directorate of Medical Services and Nursing 2016).

Since the implementation of Indonesian Health Network in 2012, the social security agency as the executor adjusted a procedure for health service started from the first level of health care. To reduce maternal and infant's mortality rate in Indonesia, Basic Emergency Obstetric Care Community Health Center (BEOC-CHC) was available in each district as a gatekeeper for the safety of mothers and children. BEOC-CHC would improve access to maternal and neonatal to cope with obstetric and neonatal emergency cases which was the most significant contributor to maternal and child mortality rate (Rahmanita and Bachtiar 2014). The aspects of patient safety in the primary health centers appeared as the part of the Regulation of Ministry of Health number 75 of 2014 , stating that every community health center in Indonesia must be accreditated at the year 2019 (Ministry of Health Republic of Indonesia 2015)

It was very few information about the adverse event in primary care (KingstonRiechers et al. 2010). Based on some researches, it was in the form of a missed or delayed diagnosis and medication management (O'Rourke 2007), medication and diagnosis errors, failures communication between the human resources (Marchon and Junior 2014), teamwork, management support, communication, staff and the value of patient safety (Molloy 2012; Walston et al. 2010,) lack of guidance, ineffective communication, lack of knowledge, and lack of quality assurance mechanisms (Pettker et al. 2009).

To provide high-quality health services and be able to compete in the global marketplace, it could be used the Malcolm Baldrige Criteria for Performance Healthcare (MBHCP). The advantages of MBHCP were its ability to provide a comprehensive and integrated assessment. MBHCP was used because of its ability to identify the strengths and opportunities for improvements, provide a framework to improve performance advantages by giving liberties to the management to implement its management strategies. An integrated management framework included every factor that defined the organization, operational processes and a clear and measurable work, increased the process speed and quality of work, building a high work system, translating the vision and mission into strategy and builds the loyalty of patients (Sadikin 2010). The purpose of this study was to determine the implementation of the seven standards of patient 
safety as the basis of patient safety model development based on Malcolm Baldrige in BEOC-CHCof Padang as the application of maternal and child protection.

\section{Methods}

This study used a descriptive exploratory study with a qualitative design. The survey was held in the Department of Health of West Sumatera as the policies holder, Department of Health of Padang as the direct supervisor and BEOC-CHC. The study was conducted from January to August 2016.

The number of informants was 25 people who were the Head of Health Registry Section, Accreditation, and Certification of Department of Health of West Sumatera, the Head of Health Services of Department of Health of Padang, the Head of Lubuk Buaya and Seberang Padang BEOC-CHC. All informants got an in-depth interview. Six health personnel from Lubuk Buaya BEOC-CHC, nine health personnel of Seberang Padang $\mathrm{BEOC}-\mathrm{CHC}$, and also 12 patients got focus group discussion (FGD). Informants were asked about the implementation of the seven standards of patient safety based on a system approach regarding input, process, and output using the guidelines derived from the hospital patient safety guidelines which were modified and adjusted based on research purposes.

The result of in-depth interviews and FGD was written in the field notes, personal documents, official documents, drawings, and photographs. Furthermore, the result would be read and analyzed. The analyzed was done by interpreting and decipher the data that had acquired into a substantive theory. The information were descriptively analyzed, summarized and presented.

\section{Results}

Based on the 25 informants in this study, the average age of the respondents was 39 years old, the youngest was 25 and the most past was 52 years old. The average length of work was 13 years, the longest was 22 years, and the shortest was two years. Almost all patients were homemakers.

Based on the results, the adverse event found last year in BEOC-CHC was medication errors and patient falls out of the bed. This adverse event was completed amicably between health centers and the patient's family. Incidents were reported in writing to the Department of Health of Padang because there were no guidelines and reporting format for adverse events. Until now, there are still no guidelines for patient safety from 
Department of Health of West Sumatra, Department of Health of Padang and BEOC-CHC in Padang about the implementation of patient safety in the BEOC-CHC.

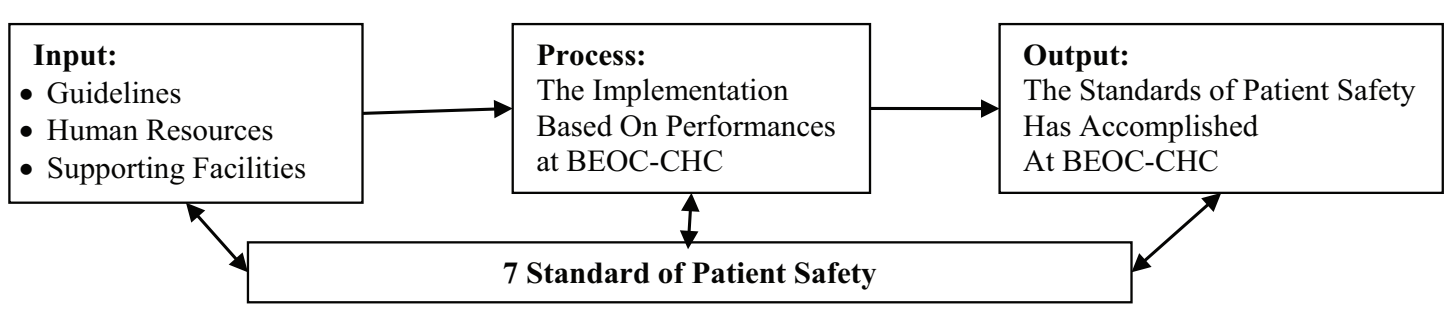

Figure 1: Thinking Flow of the Implementation of Patient Safety Standard in BEOC Health Centers.

\subsection{Patient rights}

There were no guidelines to fulfill the patient rights on BEOC-CHC yet. The doctor was in charge of service making plans of service and done assessment of patients. Medical records and informant consent became the document of services planning and implementations. In the implementation process, the information and explanations to the patients and their families about plans and results was not always given, but for every service performed was always preceded by the signing of informed consent. Patients or family were explained about the services but without being informed about the result of services, the further services plan, and the likelihood of adverse events. The output had not been running well. Patients had not been informed about the results of the services given and the possibility of adverse events.

\subsection{Educate patients and their families}

There was no specific plan to educate the patients and their families about patient safety at BEOC-CHC. The health guidance and promotion about the maternal and child safety limitary were given only to the mother through maternal classes every month, without educating the patient's family. The implementation of giving right information, transparent and honest to patients had not been done yet, but patients had already known their obligations and responsibilities. Patients understood and accepted the consequences of services, also patients and families fulfilled their financial obligations. The output had not been accomplished as well. 


\subsection{Patient safety and continual care}

Planning of the patient flow from registration until finish was conducted through the workshops in BEOC-every month. Every health personnel was in-charge from patients register until the medication and patient went home. Standard Operational Procedures (SOP) for each supporting facilities and the flowchart of patient services flows was displayed on the walls of health centers. The coordination of services was started from the registration until going home accordingly to the patient needs, but sometimes it was constrained due to the limitations of doctors. Sometimes patients were examined and given a prescription not by a doctor. The improvements of communications and transfer communication among health personnel run well. The output was going well.

\subsection{The use of improvement methods of performances to evaluate and improve patient safety}

Planning in the input by conducting performance assessment for health personnel was carried through the accreditation process of BEOC-CHC. All health personnel of BEOC$\mathrm{CHC}$ would empower all health personnel. Lubuk Buaya $\mathrm{BEOC}-\mathrm{CHC}$ was one of the best $\mathrm{CHC}$ in Padang which already had an ISO 9001 certificate. Implementation of patient safety was not done yet. There was no designing plan of improvement with the seven standards patient safety, accumulation of data, such as incident reports, risk management and audit quality of health services. Likewise, there had been no intensive evaluation of adverse events and proactively evaluate the high-risk cases, because there was no result of data analysis. Thus the change of system had not been implemented. The output had not been accomplished.

\subsection{The role of leadership to improve patient safety}

For input, the planning had not specifically for patient safety. The head of BEOC-CHC had not appointed a specialized team. There were no guidelines and documents about patient safety in the health center yet because the patient safety issue was still a new issue for the health center. The implementation also had not been done yet, shown by no interdisciplinary team, no risk identification, no mechanism of work, no responsive procedure towards incidents, no internal and external reporting mechanisms, no mechanism to handle incidents, no open collaboration and communication between units, no resource and information system, no measurable targets. The output had not been accomplished. 


\subsection{Educate the personnel about patient safety}

Plans for training and orientation process about patient safety were based on the decision from the Department of Health of Padang as the direct supervisor of BEOC-CHC. There were no guidelines and documents about patient safety. There were no integrating patient safety topics in every in-service training activities and also providing clear guidance about reporting incidents yet, but there were training about teamwork to support interdisciplinary approach and collaboration in serving patients. Based on the output, education and training programs and orientation about patient safety for new health personnel by their respective duties had not been yet accomplished.

\subsection{Communication is the key to the personnel to achieve a patient safety}

There was no specific planning for communicating about patient safety. There were no guidelines and documents about patient safety in BEOC-CHCyet because the patient safety issue was still a new issue. For the process, there was no budget available to plan and design data processing to obtain data and information related to patient safety. For the output, the implementation of data transmission was still not clear, and the information was still not accurate yet.

\section{Discussions}

Based on the research, it was obtained that the adverse event occurred at BEOC-CHC at the last year. The implementation of patient safety in BEOC-CHChad varied because of no specific guidelines available yet (Marchon and Mendes Junior 2014). In Indonesia, the regulation about the accreditation of primary health centers had just been declared recently in health regulation and the implication in the health centers was not clear yet (Ministry of Health Republic of Indonesia 2014). The risk management which was the core of the implementation of patient safety in the BEOC-CHC hadn't been running yet and the adverse event was still the fault of the individual because 'blaming culture' even was applied (Chassin 2016; Nieva and Sorra 2003).

The implementations of the seven standards of patient safety at $\mathrm{BEOC}-\mathrm{CHC}$ reviewed were with the system approach of input, process, and output. Almost all standards about patient safety (input, process, and output) were not accomplished yet. Only the third standard about patient safety and regular care systematically went well. Changes happened in health care providers; the patient became an essential aspect of the design of 
the health care and there was effort to improve the quality of health services (patientcentered care) ( Johnson et al. 2008). Patients had an essential role in helping to achieve an accurate diagnosis, in deciding on the appropriate treatment, in choosing an experienced and secured provider, in ensuring that the right treatment given, and in identifying the side effects and taking appropriate action (Vincent and Coulter 2002; Davis et al. 2007; Johnson et al. 2008). Therefore, it was essential to fulfill patients' rights and to educate patients and families. Communication between health personnel in the unit was good, but between units, it was still worse. Worse communication could lead to an adverse event (Bishop and Cregan 2015). Good communication between health personnel and with patient and family was necessary for patient safety.

Performance assessment in BEOC-CHC all this time was based on health personnel attendances. Planning performance assessments in BEOC-CHC could carry through the accreditation process of $\mathrm{CHC}$. Good health personnel performance could improve patient safety through fix inadequate work space, fulfill incomplete equipment, give adequate information from the health personnel, and fix busy and disorganized working environment (Gurses 2005). A strong, unwavering leadership and open communication and action could improve patient safety (Bagian 2005) by encouraging and ensuring the implementation of the patient safety program through the implementation of "7 Steps to the Hospital Patient Safety".

Health personnel as the practitioner must understand patient safety. Educating the health personnel about patient safety was the sixth standard of patient safety, done by planned training and orientation process about patient safety (Verbakel et al. 2014; Nieva and Sorra 2003). Since the Department of Health of Padang determined training of health personnel as the direct supervisor of $\mathrm{BEOC}-\mathrm{CHC}$, it was necessary to make a plan about training health all personnel andt patient safety in BEOC-CHC. Communication was the key to the health personnel to achieve a patient safety. Good communication between health personnel, between health personnel and patients, could reduce the adverse event. Open communication was necessary as well; open discussion would make good patient safety culture. Createing a good patient safety culture was essential to develop a model that's fit to patient safety in BEOC-CHC which could be developt as a base of Malcolm Baldridge performance.

\section{Conclusions}

In general, it could be seen that the 7 standards of patient safety were based on patient safety guidelines by KPPRS. It was only the third standard about patient safety and continuous care that had been running systematically, started from input, process until its 
output, while the other patient safety standards (number 1, 2, 4, 5, 6, and 7) hadn't been accomplished yet. It was required a patient safety system that matched the conditions of the BEOC-CHC based on Malcolm Baldridge performance as the standard of the performance of the organization which was applied to the patient safety performance.

\section{Acknowledgements}

This research is a part of Competitive Professor Grant Andalas University number 81/UN.16/HKRGB/LPPM/2016. Researchers would like to thank to dr. Adang Bachtiar DSc., Prof. Dr. dr. Herkutanto SpF SH LLM FACLM, Prof. dr. Nur Indrawati Liputo SpGK Ph.D., Nilda Tri Putri ST, MT Ph.D. BEOC-CHC Seberang Padang and Lubuk Buaya, Department of Health Sumatera Barat and Padang, and Andalas University.

\section{References}

[1] Bagian, James P. 2005. "Patient Safety: What Is Really an Issue?" Frontiers Of Health Services Management No. 22 (1):3-16.

[2] Bishop, Andrea C., and Brianna R. Cregan. 2015. "Patient safety culture: finding meaning in patient experiences." International Journal of Health Care Quality Assurance no. 28 (6):595-610.

[3] Chassin, Mark R. 2016. "The Need For A Paradigm Shift In Healthcare Culture: Old Versus New." High-Reliability Organizations: A Healthcare Handbook for Patient Safety \& Quality:3.

[4] Damayanti, Mia, and Meta Rosdiana. 2016. "The Influence Of Mother's Legal Assets On Mother's Anxiety In Dealing With Labor Process In Bpm Ch Mala Palembang" Journal of Health no. 7 (2):250-254.

[5] Davis, Rachel E, Rosamond Jacklin, Nick Sevdalis, and Charles A Vincent. 2007. "Patient involvement in patient safety: what factors influence patient participation and engagement?" Health Expectations no. 10 (3):259-267.

[6] Findyartini, Ardi, Rita Mustika, Estivana Felaza, Herqutanto, Enggar Sari Kesuma Wardhani, Detty Iryani, Hendriati, Efrida, Tonang D Ardyanto, Krisna Yarsa Putra, Fikar Arsyad Hakim, and Amandha Boy Timor. 2015. Training Module for Patient Safety Trainers: Collaboration Field Education Project P4K-RSP.Fleming, Mark. 2005. "Patient Safety Culture Measurement an Improvement: A "How to Guide."” no. 8.

[7] Gurses, Ayse Pinar. 2005. "Performance obstacles and facilitators, workload, quality of working life, and quality and safety of care among intensive care nurses." Ph.D. thesis., The University of Wisconsin - Madison, Ann Arbor. 
[8] Johnson, Bev, Marie Abraham, Jim Conway, Laurel Simmons, Susan Edgman-Levitan, Pat Sodomka, and D Ford. 2008. "Partnering with patients and families to design a patient-and-family-centered health care system." Bethesda MD: Institute for FamilyCentered Care.

[9] Kingston-Riechers, J, M Ospina, E Jonsson, P Childs, L McLeod, and J Maxted. 2010. "Patient safety in primary care." Edmonton AB: Canadian Patient Safety Institute and BC Patient Safety and Quality Council.

[10] Kohn, Linda T, Jannet M.Corrigan, and Molla S.Donaldson. 2000. To Err is Human: Building a Safer Health System. Washington: National Academy Press.

[11] Marchon, Simone Grativol, and Walter Vieira Mendes Junior. 2014. "Patient Safety In Primary Health Care: A Systematic Review." Cadernos de saúde pública no. 30 (9):1815-1835.

[12] Minister of Health of the Republic of Indonesia. 2014. "Regulation of the Minister of Health of the Republic of Indonesia No 75 of 2014 on Community Health Centers" Jakarta.

[13] Minister of Health of the Republic of Indonesia. 2015. "Regulation of the Minister of Health of the Republic of Indonesia Number 46 the Year 2015 on Puskesmas Accreditation, First Clinic, Independent Practice Place of Doctor, and Dentist Self Practice Place". Jakarta.

[14] Patricia A Molloy, "Examining the relationship between work climate and patient safety among nurses in acute care settings" (2012). Dissertations and Master's Theses (Campus Access).Paper AAl3503408. http://digitalcommons.uri.edu/ dissertations/AAl3503408

[15] Nieva, VF, and J Sorra. 2003. "Safety culture assessment: a tool for improving patient safety in healthcare organizations." Quality and Safety in Health Care no. 12 (suppl 2):ii17-ii23.

[16] O'Rourke, M. 2007. "The Australian Commission on Safety and Quality in Health Care agenda for improvement and implementation." Asia Pacific Journal of Health Management no. 2 (2):21.

[17] Pettker, Christian M, Stephen F Thung, Errol R Norwitz, Catalin S Buhimschi, Cheryl A Raab, Joshua A Copel, Edward Kuczynski, Charles J Lockwood, and Edmund F Funai. 2009. "Impact of a comprehensive patient safety strategy on obstetric adverse events." American Journal Of Obstetrics And Gynecology no. 200 (5):492. e1-492. e8.

[18] Rahmanita, Desi Rosalia Putri, and Adang Bachtiar. 2014. "Assessment of Service Performance of Basic Emergency Neonatal Obstetrics at Puskesmas Poned Tanah 
Sareal Bogor City with Balanced Scorecard Approach in 2014" Faculty of Public Health University of Indonesia.

[19] Sadikin, Iskandar. 2010. Malcom Baldrodge National Quality Award (MBNQA). Surabaya: Lembayung Central Indonesia.

[20] Sub-Directorate of Medical Services and Nursing. 2016. Evaluation of E-Reporting Reporting Incident Reporting of Hospital Patient Safety Until February 2016. In Patient Safety Workshop at Hotel Horizon Bogor 2-4 March 2016, edited by Secretariat of Patient Safety Committee RS. Bogor.Top, Mehmet, and Sabahattin Tekingündüz. 2015. "Patient Safety Culture in a Turkish Public Hospital: A Study of Nurses' Perceptions About Patient Safety." Systemic Practice and Action Research no. 28 (2):87-110. doi: http://dx.doi.org/10.1007/s11213-014-9320-5.

[21] Verbakel, Natasha J, Maaike Langelaan, TJ Verheij, Cordula Wagner, and Dorien LM Zwart. 2014. "Improving patient safety culture in primary care: a systematic review." J Patient Saf (March (18)).

[22] Vincent, Charles A, and Angela Coulter. 2002. "Patient safety: what about the patient?" Quality and Safety in Health Care no. 11 (1):76-80.

[23] Walston, Stephen L, Badran A Al-Omar, and Faisal A Al-Mutari. 2010. "Factors Affecting The Climate Of Hospital Patient Safety: A Study Of Hospitals In Saudi Arabia." International Journal of Health Care Quality Assurance no. 23 (1):35-50. 